\title{
REFLEXOS DO PLANO DE NEGÓCIOS EM MICROEMPRESAS DE VENDA NOVA DO IMIGRANTE
}

\author{
Márcia Roberta da Silva Louzada ${ }^{1}$ \\ José Mauro de Sousa Balbino² \\ Drieli Rossi ${ }^{3}$ \\ Evandro de Andrade Siqueira ${ }^{4}$ \\ Lucas Louzada Pereira ${ }^{5}$
}

RESUMO: Empreender é uma arte de aplicar os conhecimentos adquiridos ao longo da vida em momentos propícios para atingir fins específicos. Mais que gestor, o empreendedor é um visionário que identifica oportunidades e traça caminhos para alcançar seus objetivos. Este trabalho buscou analisar o perfil do empreendedor vendanovense e sua visão sobre a importância da adoção do plano de negócios e ao mesmo tempo identificar os possíveis impactos sofridos por empresas que não o utilizaram. Como ferramenta metodológica para desenvolvimento da pesquisa, utilizou-se uma análise descritiva com aplicação da pesquisa de campo e como ferramenta de coleta de dados, adotou-se o questionário semiestruturado. Os resultados indicam que os empreendedores vendanovenses consideram o plano de negócio como uma ferramenta válida para o suporte na abertura e condução do empreendimento, sendo um instrumento auxiliador ao negócio em que estes atores estão inseridos.

PALAVRAS-CHAVE: Empreendedorismo; Estratégia de Negócios; Gestão Empresarial.

\footnotetext{
${ }^{1}$ Faculdade de Venda Nova do Imigrante/FAVENI, Brasil. E-mail: kallylintu@hotmail.com.

2 Instituto Capixaba de Pesquisa, Assistência Técnica e Extensão Rural (INCAPER). Centro Regional de Desenvolvimento Rural, Brasil. E-mail: jmsbalbino@hotmail.com.

${ }^{3}$ Faculdade de Venda Nova do Imigrante - FAVENI, Brasil. E-mail: drielirossi@hotmail.com.

${ }^{4}$ Instituto Federal do Espírito Santo, Brasil. E-mail: evandro.siqueira@ifes.edu.br.

5 Instituto Federal do Espírito Santo/Campus Venda Nova do Imigrante/Departamento de Ciência dos Alimentos, Brasil. E-mail: lucas.pereira@ifes.edu.br.
} 